\title{
Climate change and related management issues in the mountains of Southeastern Europe - the Pirin National Park in Bulgaria
}

\section{Karsten Grunewald}

Keywords: adaptation, Balkans, ecosystem services, habitats, measures, monitoring, vulnerability

\section{Abstract}

Investigation of climate change in mountains of southwest Bulgaria suggests that the identified changes could have a long-term effect on the ecosystems and their services in the region. This paper aims to highlight some of the main threats that alpine landscapes in Pirin National Park might face, given the anticipated climate changes, and to document the potential prediction of vulnerability as well as the need to establish adaptive management.
Profile

Protected area

Pirin National Park

Mountain range

Pirin

Country

Bulgaria

\section{Introduction}

The predicted increase in global temperature and the changes in the amount of precipitation represent a significant challenge, not only for habitats in protected areas (Andrade et al. 2010) but also for intelligent landuse strategies. In this context the concept of adaptative management of nature reserves under conditions of climate change can become a potential way to proactively respond to climate change influences (Fazey et al. 2009). State-run protected areas, especially national parks, have a special role to play here because conservation and local activities (e. g. tourism, water management, regional development) should be linked in so-called win-win situations and management efforts can serve as models.

High mountain regions and their hypsometric zoning are of climate change interest because they are very sensitive ecosystems and ecological boundaries are especially affected by changes (e.g. Beniston 2003). On the one hand, slight temperature variations shift cultivation limits and affect runoff regimes as well as slope stability or other ecosystem services / disservices. On the other hand, studies (e.g. Ohmura 2012; Rangwala \& Miller 2012) have found that the variability of temperature in climate time scales tends to increase with altitude and this should be taken into account in considering and planning for climate change impacts in mountain regions.

The focus of this paper is on identifying the extent of climate change as well as related impacts, ways in which stakeholders could react to threats and aspects that could be significant in selecting the adequate adaptative management practices. For the purpose of this study we chose southwest Bulgaria with Pirin National Park (NP) as a case in point. The ecosystem structures, processes and dynamics, nature protection

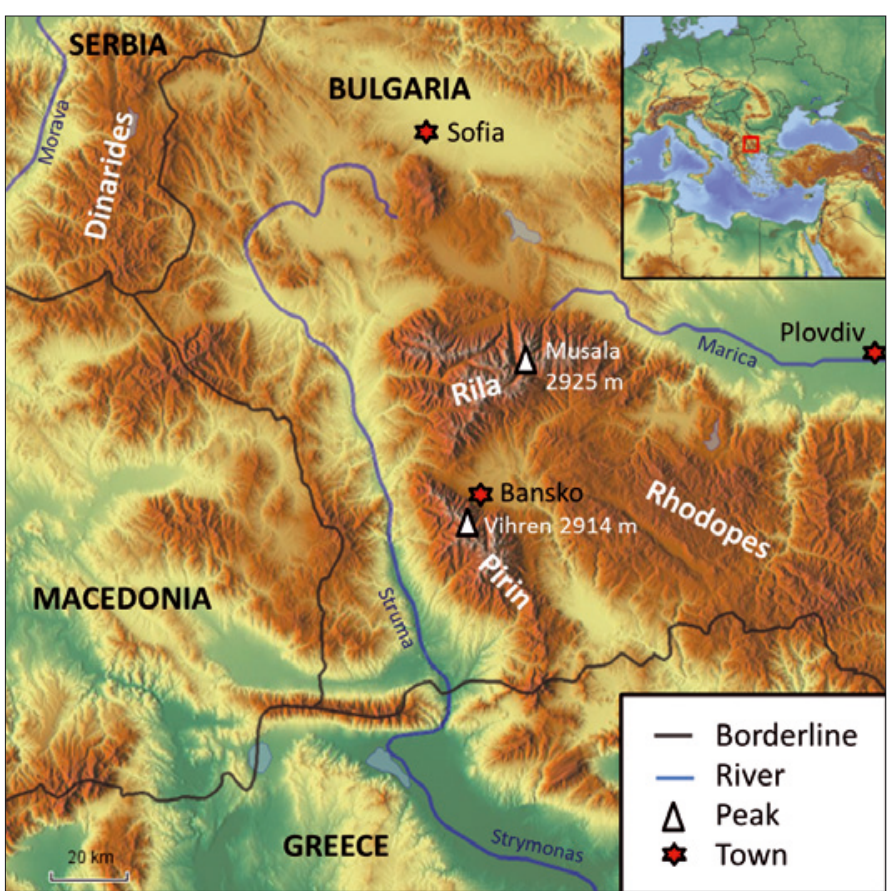

Figure 1 - Location and structure of the study area southwestern Bulgaria: a mosaic of mountains, basins and valleys. Source: Stepmap.com

issues, as well as the aspects of demand for resources in this region can be seen as representative for mountain areas of the Balkan Peninsula (Grunewald \& Scheithauer 2011).

The mountains in southwestern Bulgaria are an important ecological link between the Mediterranean region and the mid-latitudes (Figure 1). They form the transition between the southern European areas, where height and thickness of the trees at the timberline is predominantly controlled by the water supply, and the summer-humid high mountains of Europe, where the summer temperatures drive tree growth (Grunewald \& Scheithauer 2011). In princi- 


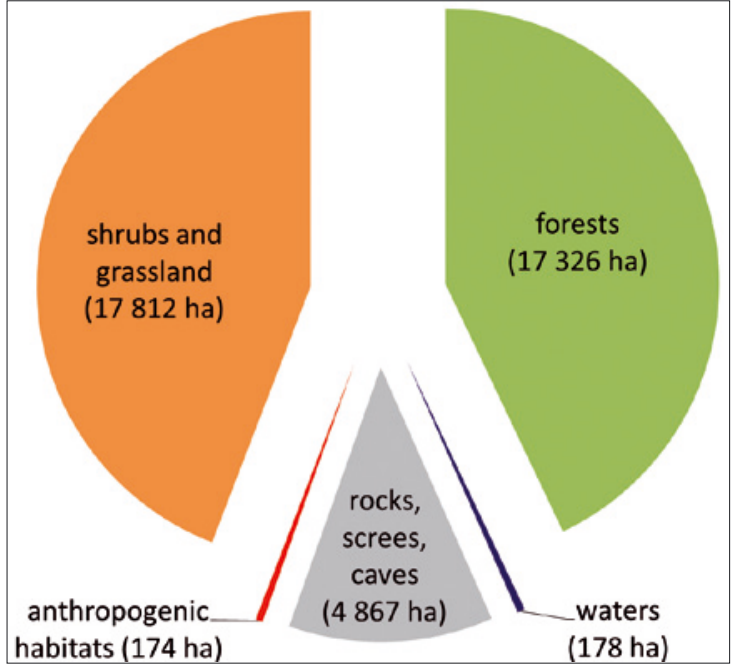

Figure 2 - Share of ecosystem types in Pirin NP (adapted from Anonymous 2003)

ple, high mountain regions receive ample precipitation and experience permanently low temperatures. In the southern peripheral areas, however, highlands and lower areas are dry and warm (for instance in northern Greece). Comparatively small changes in climate may have an extreme effect on the environmental conditions and can upset balances.

\section{Characteristics of Pirin NP}

The mountains in southwestern Bulgaria are part of the Rhodopes Massif (also Rila-Rhodopes Massif or Thracian Massif) and the Serbo-Macedonian massif. The Pirin Mountains soar up from their surrounding valleys and basins as a single range. Its main axis has a NW-SE-expansion of approx. $70 \mathrm{~km}$ and a mean width of $35 \mathrm{~km}$ (Figure 1). More than 50 peaks within the Pirin Mountains reach altitudes above $2600 \mathrm{~m}$, with Vihren the highest peak at $2914 \mathrm{~m}$.

Forests dominate in the region, agriculture and settlement areas are confined to basins and valleys. In the study area of the northern Pirin the available resources led to the development of four main branches of economic activity: i) forestry; ii) water management for irrigation, drinking water, energy generation and, most recently, for artificial snow making; iii) mountain pastures; and iv) tourism.

The area of Pirin NP includes two UNESCO biosphere reserves and covers 40356 ha or $22 \%$ of the whole Pirin Mountains area. The NP is integrated in ecological networks as a member of the EUROPARC Federation, approved by IUCN and included on the UNESCO World Heritage list. Implementing the management plan 2004-2013 for Pirin NP was a milestone, realized with financial help and the assignment of personnel by Switzerland (Anonymous 2003). The plan includes conservation, landscape development, as well as the use of resources and tourism so as to provide for an integrative review. The NP serves as a socioeconomic factor of regional development and

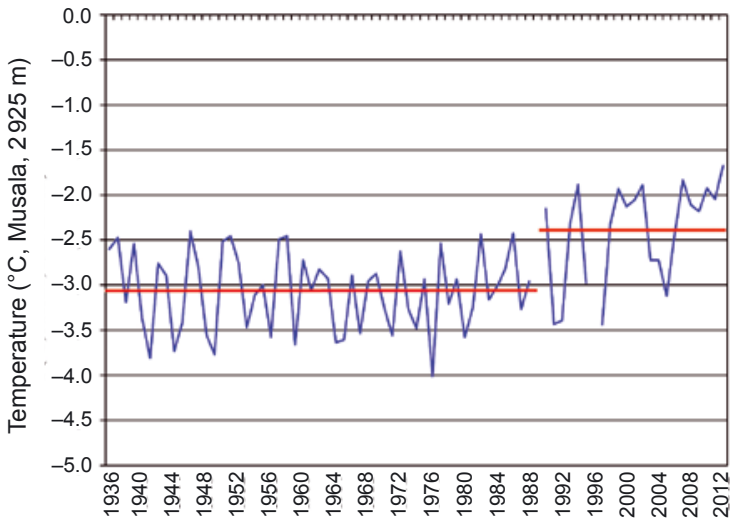

Figure 3 - Evolution of annual mean air temperature at Musala Peak for the period 1936-2012 (mean 1936-1989: $-3.07^{\circ} \mathrm{C}$; mean $1990-2012:-2.40{ }^{\circ} \mathrm{C}$ )

constitutes a binding operational instrument. Modelled on the Alpine Convention (1991), the management plan became the basis for sustainable development in the mountain region.

Geoecotypes were mapped in the NP following the classification of Palaearctic Habitats (Nature and Environment No. 78/96). Figure 2 illustrates the predominance of forests and of open areas above timberline. Habitats with anthropogenic impact account for $2.2 \%$ of the whole area, which makes the study area particularly suitable for monitoring natural, mainly climate driven, changes.

\section{Regional climate change aspects}

Brown \& Petkova (2007), Grunewald et al. (2009) and Najarov (2012a, 2012b) have presented comprehensive studies on climate change in Bulgarian mountains. The main findings for the measured period 1931-2012 are:

\section{Annual air temperatures}

There is definite warming in high-mountain parts of southwestern Bulgaria during the measured period, with an increase of about $0.7^{\circ} \mathrm{C}$. The main increase started in the second half of the 1970s and strengthened to 2012. Figure 3 shows that annual mean air temperature jumped to a new level during the last two decades. 2012 was the warmest recorded year.

\section{Monthly air temperatures}

The months of June, July, August and January are the main contributors to the warming tendency. One cause is the reorganization of atmospheric circulation in those months.

\section{Threshold values and extremes}

Musala Peak station, $2925 \mathrm{~m}$, shows the following extremes for the period 1973-2006:

- a significant shift from cold to warm days;

- an increase of days with frost change, especially in April and September / October; 


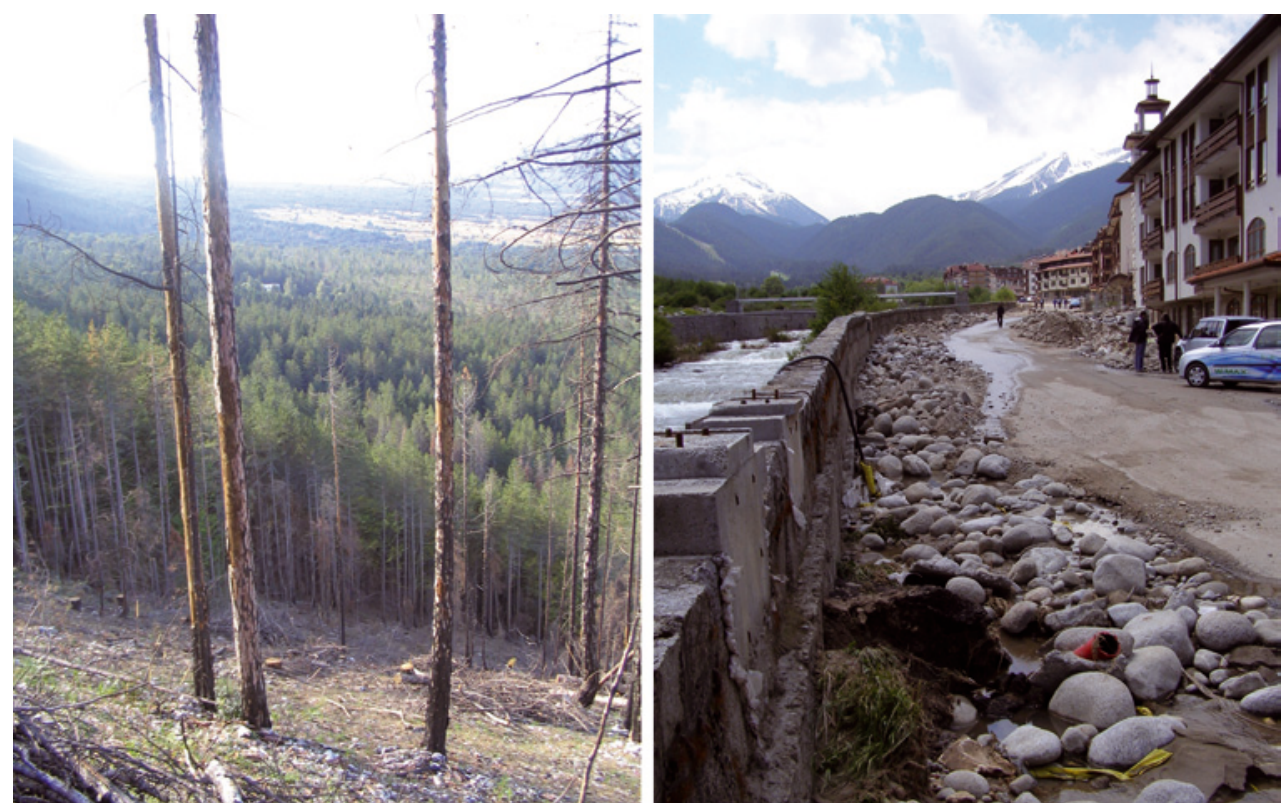

Figure 4 - Forest destroyed by fire (Sept. 2005) and flood event damages in Pirin NP / Bansko (May 2010) - natural events or signs of increasing weather extremes? (C) K. Grunewald

- a general decrease of days with temperatures below $0{ }^{\circ} \mathrm{C}$;

- a significantly longer growing season $\left(>5^{\circ} \mathrm{C}\right)$;

- a trend towards shorter winters and longer summers.

\section{Precipitation measurements}

If one considers only the climatically normal period from 1961 to 1990, one will find a relatively strong negative precipitation trend in the study area, primarily in winter. But this trend could not be detected for long-term series. Humid and dry years alternate on a relatively frequent basis. The analysis of monthly precipitation reveals possible trends for June (decrease during the first vegetation period) and September (increase), but the statistical significance of these trends is fairly low.

\section{Snow cover}

Brown \& Petkova (2007) could not characterize a variation in the start of the thawing period in spring nor could they find a significant influence of recent global warming. However, an analysis of the number of days with / without snowfall at Musala Peak station during the 1973-2006 period (Grunewald et al. 2009) showed that the annual number of days with snowfall decreases over time as well as for the summer and autumn periods.

\section{Global climate models}

Najarov (2012c) succeeded in a statistical downscaling of global climate models and some projections for air temperature and precipitation in Bulgarian mountains. The results point to mixed future changes of air temperature at all modeled high-mountain stations. Mean annual temperatures are expected to rise only by $0.2{ }^{\circ} \mathrm{C}$ (Musala Peak) in the period 2075-2084. Other larger-scale climate projections (Lelieveld et al.
2012) indicate a regional warming for Bulgaria ranging from $1{ }^{\circ} \mathrm{C}$ to $3{ }^{\circ} \mathrm{C}$ in the near future $(2010-2039)$, to $3-5{ }^{\circ} \mathrm{C}$ in the mid-century period $(2040-2069)$ and $3.5-7^{\circ} \mathrm{C}$ by the end of the century $(2070-2099)$. Future trends in precipitation are mixed both in spatial and in temporal terms (Najarov 2012c).

\section{Selected impacts of climate change}

Climate change has already had and will continue to have important regional impacts on ecosystems, ecosystem services and human benefits. Detected changes in threshold values and extremes should affect the morphological stability of this alpine area, the development of soils, micro-organisms, vegetation or species composition, as well as the water retention capacity and snow cover period. Warming leads to a change in the distribution of trees and plants, for example, the mountain pine (Pinus mugo) is now growing at higher altitudes than before in the northern Pirin Mountains (Grunewald \& Scheithauer 2011).

Bosnian pine (Pinus beldreichii) and Macedonian pine (Pinus peuce) are the most common species at the recent timberline around $2100 \mathrm{~m}$ in the Pirin Mountains. Both endemic and long-lived species are of great importance for dendroclimatological regional studies (e.g. Panayotov et al. 2010). Despite drier and warmer conditions in southwestern Bulgaria during the last 50 years, Pinus heldreichii showed an increasing average growth rate, it endures harsh conditions quite well. Competition with species of the montane level as a consequence of a hypsometric shift of vegetation levels toward the summit is unlikely. So Pinus heldreichii would be a winner under climatic changes (Grunewald \& Scheithauer 2011).

We also investigated the southernmost glaciers in Europe in terms of climate change. In the Pirin 

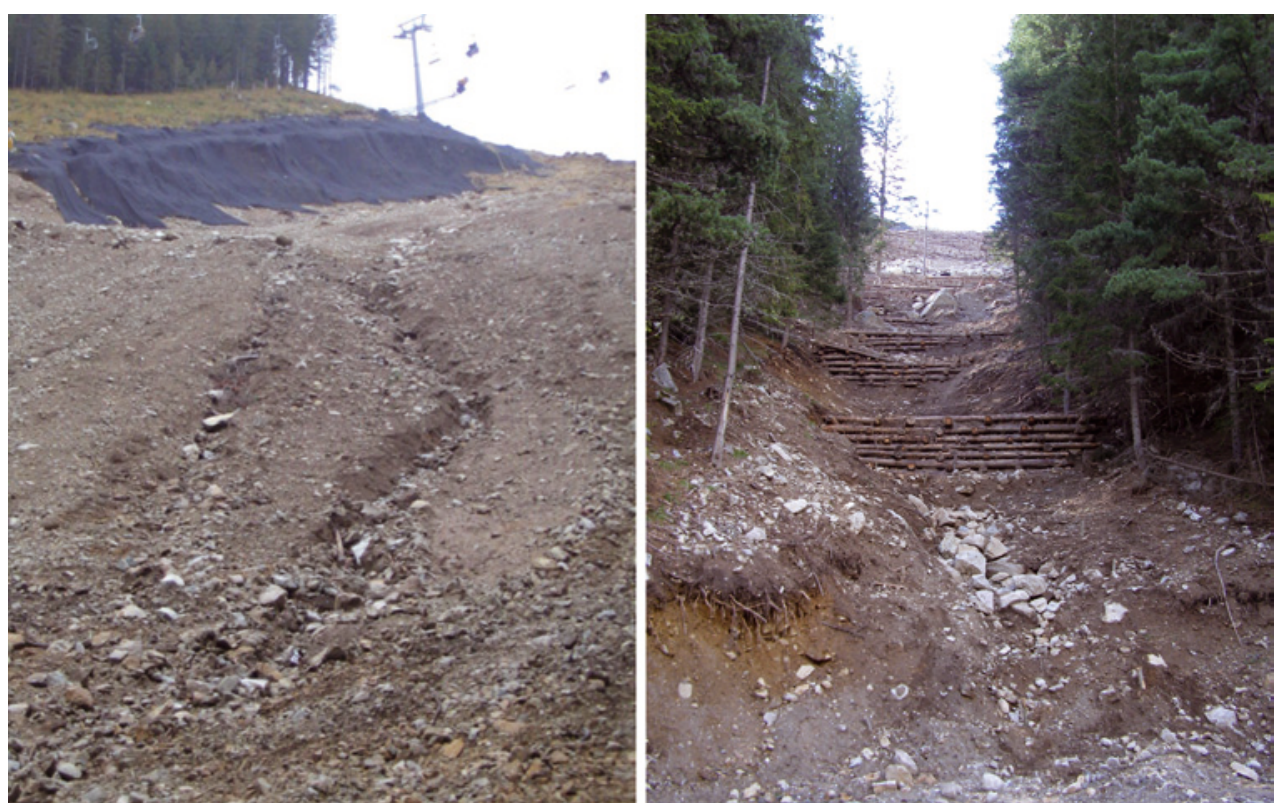

Figure 5 - Logging of primeval forests for skiing facilities (left); slope instability and erosion in Pirin NP (right). (C) K. Grunewald

Mountains the glacieret Sneshnika is under special observation as small glacier features respond quickly to weather extremes. However, despite the trend towards warmer years since the late 1970 s, the local glacierets have still survived - even after some of the hottest summers on record (Grunewald \& Scheithauer 2010). A further temperature increase by more than $2{ }^{\circ} \mathrm{C}$ in the $21^{\text {st }}$ century, as predicted, expects the Pirin glacierets to disaggregate in situ. In future, however, increasing winter precipitation is likely to result in greater snow accumulation. In the short term, this snow accumulation may exceed snow mass lost by summer ablation so that, in protected sites, small snow / firn patches will survive.

A shift to warmer and dryer conditions in the mountains of Southeastern Europe entails changes in geofactors - as described above - and ecosystem services, as well as dis-services such as floods and droughts, heat stress or increasing forest fires (Figure 4). Climate change could also have socioeconomic consequences, for instance on the reliability of snow cover in the Bulgarian ski resorts and on the sustainability of water supply in the currently booming Bansko ski resort, situated at the foot of the northern Pirin Mountains. A significant modification in the southwestern Bulgarian mountains water resources, which are a regional water tower, would have far-reaching effects on the water reservoirs and the irrigated agriculture in northern Greece.

\section{Adaptation and management issues}

Effects of weather events and climate changes largely depend on the degree of vulnerability and exposure of society to these events. It is therefore possible to mitigate consequences and risks, e.g. through appropriate and early stage risk communication, warn- ing systems and prevention strategies. At the local level it is important to inform the public, to involve them in decision making and enable social learning processes. Adequate monitoring of climate and landscape change forms the basis for such measures (repeated inventory, timely detection of significant ecosystem components and services; Pauli et al. 2012; Grunewald \& Bastian 2013). The National Park Service (Anonymous 2003) launched an appropriate protection, monitoring and management programme especially for habitats in protected areas (Natura 2000 sites) and for the forest communities (fire protection).

Direct technical climate measurements, however, still constitute an exception in Pirin as in mountain regions across the Balkans. Local meteorological case studies with modern equipment at the timberlines are rare. This hampers scientific climatological and hydrological statements. Hence there is also a lack of applied information about evaporation values, flood dangers, weather forecasts for tourists and so on. We helped to improve the situation by establishing automated weather stations, a gauging station and data logger at the timberline in the northern Pirin Mountains.

The protection of fragile ecosystems is central in high mountains. The subalpine and alpine regions in southeastern Europe usually enjoy the highest level of protection, as exemplified in the zoning of Pirin NP:

reserve zone and zone of limited human impact including the UNESCO MAB biosphere reserves Bayuvi-Dupki-Dzhindzhirica and Yulen (34.2\% of the total park area);

- zone of conservation of forests, ecosystems and recreation and zone of sustainable use of open areas and recreation $(62.5 \%$ of the total park area); - tourism zone and zone of buildings and facilities (3.3 $\%$ of the total park area). 
The zones are clearly defined in terms of the mountainous nature and ecology, and the territory is of sufficient size to capture the natural assets of Pirin. Adequate boundaries have been established to include the most remote areas of the interior of the NP and exclude adjacent areas that are not compatible with the conservation aims and world heritage status due to impacts on integrity especially from ski development. The NP administration is responsible for appropriate measures, supported by many social initiatives (governance, policy mix).

Mountains are gradually deteriorating under the effects of anthropogenic stress and climate change. The impact of the combined effects of these factors on the ecosystems and biodiversity becomes more and more visible (Figure 5). Currently tourism is the region's motor for socioeconomic development and the traditional mountain agriculture is receding. Since the fall of the Iron Curtain the economic role model of the Alps serves as a guide for mountain regions in southeastern Europe. It was a quick learning process to understand that ski and spa tourists bring significantly more money than hikers and eco-tourists (Grunewald \& Scheithauer 2008). Adaptation to climate change usually takes the form of creating alternative options for tourism and / or introducing technical upgrades (e.g. artificial snow making).

\section{Conclusion}

Climate change may change the capacity of mountain landscapes to generate wealth and to provide a good livelihood. Such impacts will add further pressure to both social and natural systems in these regions, so there is the need to promptly conduct proactive climate adaption plans. Apart from climate change, the development of tourism infrastructure is an important driver of biodiversity change in the region under study. Mountain towns in the region, e.g. Bansko, could even benefit from summer tourists in future when settlements at lower altitudes will suffer more from heat stress.

Conservation strategies have to aim first and foremost at protection and long-term promotion of biodiversity and ecosystem services by exploiting the possibilities of the established regulations. Because of the wide range of climatic changes and the scope of their effects, cooperation at local, regional and supraregional level is indispensable. The creation of large, ecologically diverse and extensively used protected areas or unmanaged landscape sections can be very useful in this respect. The consolidation of effective biocoenosis connections between vegetation sites as well as transboundary networks of protected areas may improve the success of migrations enforced by climatic changes.

While policy and economic demands have driven regional development and the different sectors in the past, it is expected that climate change will severely affect not only key sectors (e. g. tourism, hydro-electric power generation, etc.) but may also lead to increasing competition for resources between sectors. Integrated, stakeholder-based management concepts as well as public support will be an increasingly essential prerequisite for effective adaptation to changes.

\section{References}

Andrade, P.A., F.B. Herrera \& G.R. Cazzola (eds.) 2010. Building Resilience to Climate Change: Ecosystem-based adaptation and lessons from the field. Gland, Switzerland: IUCN.

Anonymous 2003. National Park Pirin Management Plan 2004-2013. Ministry of Environment and Water, NP Direction, Bansko.

Beniston, M. 2003. Climatic change in mountain regions: A review of possible impacts. Climatic Change 59: 5-31.

Brown, R.D. \& N. Petkova 2007. Snow cover variability in Bulgarian mountainous regions, 1931-2000. International Journal of Climatology 27: 1215-1229.

Fazey, I., J. Gamarra, J. Fischer, M. Reed, L. Stringer \& C. Mike 2009. Adaptation strategies for reducing vulnerability to future environmental change. Frontiers in Ecology and the Environment 8 (8): 414-422.

Grunewald, K. \& O. Bastian (eds.) 2013. Ökosystemdienstleistungen - Konzept, Methoden und Fallbeispiele. Heidelberg.

Grunewald, K. \& J. Scheithauer 2008. What are mountain regions in Southeast Europe able to learn from the Alps? (Bansko/Pirin, Bulgaria). In: Borsdorf, A., J. Stötter \& E. Veulliet (eds.), IGF-Forschungsberichte 2: 295-302.

Grunewald, K. \& J. Scheithauer 2010. Europe's Southernmost Glaciers: Response and Adaptation to Climate Change. Journal of Glaciology 56 (195): 129-142.

Grunewald, K. \& J. Scheithauer 2011. Landscape development and climate change in Southwest Bulgaria (Pirin Mts.). $1^{\text {st }}$ Edition.

Grunewald, K., J. Scheithauer, J.M. Monget \& D. Brown 2009. Characterization of contemporary local climate change in the mountains of southwest Bulgaria. Climatic Change 95 (3-4): 535-549.

Lelieveld, J., P. Hadjinicolaou, E. Kostopoulou, J. Chenoweth, M. El Maayar, C. Giannakopoulos, C. Hannides, M.A. Lange, M. Tanarhte, E. Tyrlis \& E. Xoplaki 2012. Climate change and impacts in the Eastern Mediterranean and the Middle East. Climatic Change 114: 667-687.

Najarov, P. 2012a. Changes in air temperatures and atmosphere circulation in high mountainous parts of Bulgaria for the period 1941-2008. Journal of Mountain Science 9: 185-200.

Najarov, P. 2012b. Variations in precipitation amounts, atmosphere circulation and relative humidity in high mountainous parts of Bulgaria for the period 1947-2008. Theoretical and Applied Climatology 107 (1-2): 175-187. 
Najarov, P. 2012c. Bulgarian mountains air temperatures and precipitation - statistical downscaling of global climate models and some projections. Theoretical and Applied Climatology 110 (4): 631-644.

Ohmura, A. 2012. Enhanced temperature variability in high-altitude climate change. Theoretical and Applied Climatology 110 (4): 499-508.

Panayotov, M., P. Bebi, V. Trouet \& S. Yurukov 2010. Climate signal in tree-ring chronologies of Pinus peuce and Pinus heldreichii from the Pirin Mountains in Bulgaria. Trees 24 (3): 479-490.

Pauli, H., M. Gottfried, S. Dullinger et al. 2012. Recent Plant Diversity Changes on Europe's Mountain Summits. Science 336 (6079): 353-355.

Rangwala, I. \& J.R. Miller 2012. Climate change in mountains: a review of elevation-dependent warming and its possible causes. Climatic Change 114: 527-547.

The Alpine Convention 1991. Available at: http://www.alpenkonvention.org/index (accessed: 17/09/07).

\section{Author}

Karsten Grunewald

studied geography, mathematics, education science at the University of Potsdam; PhD and Habilitation in physical geography/geoecology; senior lecturer, TU Dresden; since 2009 senior researcher and head of projects at IÖR in Dresden. Key research areas: analysis and quantitative description of landscape ecosystems; landscape and climate change; assessment of ecosystem services. Leibniz-Institute of Ecological Urban and Regional Development. 01217 Dresden, Weberplatz 1, Germany. 